\section{Definite, probable or dubious: antioxidants trilogy in clinical dentistry}

\author{
S. Carnelio,' S. A. Khan² and G. Rodrigues ${ }^{3}$
}

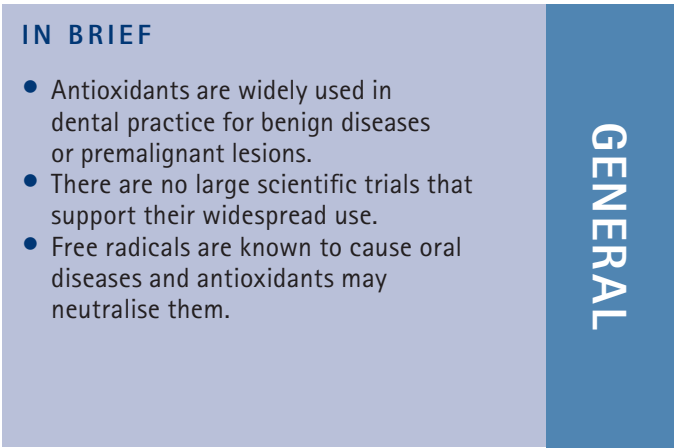

VERIFIABLE CPD PAPER

\begin{abstract}
Recent years have shown the presence of free radicals in causation and progression of various dental diseases and antioxidant usage in dental therapeutics. Antioxidant micronutrients are important not only for limiting oxidative and tissue damage, but also in preventing increased cytokine production, which is a result of prolonged activation of the immune response. There has been a widespread availability and clinical claims on the safety and efficacy of antioxidants. However, lack of randomised controlled trials in dental research limits their usage. There is a substantial gap between these clinical claims and efficacy/safety of antioxidants in dental therapeutics which needs to be addressed. This article highlights the clinical significance of antioxidant therapy in dental practice and touches upon controversial areas and research lacunae. An evidence based approach for making recommendations about antioxidant usage and efficacy in routine dental practice seems to be the need of the hour.
\end{abstract}

\section{INTRODUCTION}

Antioxidants are being widely used in routine general clinical practice. An increased interest in the role of free radical oxidative damage in human diseases along with an upsurge in research implies its potential in dental practice too. Consumption of antioxidant supplements in developed countries has become widespread with about one third of adults being 'addicted' to them. ${ }^{1}$ However, as dental research in this area is still unfocussed due to limited number of studies/randomised controlled trials (RCTs), definitive conclusions on their safety and efficacy cannot be commented upon. A need for confirmatory evidence and addressing the safety issues with a focus on oral healthcare seems to be an important requirement.

\footnotetext{
Department of Oral and Maxillofacial Pathology, Manipal College of Dental Sciences, Manipal University, Manipal, India; ${ }^{2}$ Department of Pharmacy Practice, SS Cancer Research Centre, Manipal, India; ${ }^{3 *}$ Division of General Surgery, Queen's Medical Centre, Nottingham University Hospitals, Nottingham NG7 2UH ${ }^{*}$ Correspondence to: Dr Gabriel Rodrigues Email: rodricksgaby@yahoo.co.in
}

\section{Refereed Paper}

Accepted 24 October 2007

DOI: $10.1038 /$ bdj.2007.1186

${ }^{\circledR}$ British Dental Journal 2008; 204: 29-32

\section{Rationale of antioxidants usage in dentistry}

Free radicals seem to influence many oral diseases, most commonly periodontitis. Though oxidative stress is implicated in the pathogenesis of periodontitis, it is seen that the total antioxidant capacity of gingival crevicular fluid (GCF) volume and plasma appears compromised. ${ }^{2}$ The periodontal tissues also provide an ideal medium to study the mechanisms of reactive oxygen species (ROS) mediated tissue damage and of antioxidant defence in response to bacterial colonisation. ${ }^{3}$ Ascorbic acid deficiency has been shown to be a conditioning factor in the development of gingivitis. ${ }^{4}$ As initial studies showed partial response to non surgical interventions in these conditions, product manufacturers have looked at the use of herbs or supplements in toothpastes, mouth rinses and other products for the control of periodontal disease. ${ }^{5}$ Aloe vera, star anise oil, myrrh gum, calendula extract, ammonium glycyrrhizate (from licorice root), fennel oil, melaleuca alternifolia (tea tree oil), and neem extract are among the ingredients used for control of periodontal disease. ${ }^{6}$

Peri-implant disease is initiated and perpetuated by a small group of pre- dominantly gram negative, anaerobic, or microaerophilic bacteria that colonise the subgingival area. Numerous molecular species appear in the inflamed tissues, among which are reactive species such as free radicals and ROS. Hence, treatment of peri-implant disease involves adjuvant antioxidants supplementation. It has been documented that there is an increased level of total protein and total antioxidant values in the saliva in dental caries. ${ }^{7}$ Observational studies show maximum inflammatory changes of periodontium in the eighth month of pregnancy with an amelioration shortly before delivery. Simultaneous follow up of the physiological levels of vitamin E and $A$ in four week intervals showed the decline of the mean levels of both vitamins in the course of the eighth month and their marked elevation shortly before delivery. ${ }^{8}$ Inconclusively, these studies show the role of antioxidant supplementation in prevention and/or management of numerous dental disorders.

\section{Mechanism of action of antioxidants}

Antioxidants may be regarded as those substances which when present even at low concentrations with those of an oxidisable substrate will significantly delay 
or inhibit oxidation of that substrate. Free radicals which are harmful usually arise during metabolism and sometimes the immune system cells create them to neutralise harmful pathogens. Environmental factors like pollution, radiation and smoking may spawn free radicals. Antioxidants neutralise free radicals by donating one of their electrons, ending the electron stealing reaction. The antioxidant nutrient, however, does not become a free radical by donating an electron because they are stable in either form. Important antioxidants include: (1) the chain breaking or scavenging ones like vitamin E (alpha tocopherol), vitamin C (ascorbic acid), vitamin A (beta carotene), urate and bilirubin; (2) those substances containing thiol groups - the 'preventative antioxidants', that function largely by sequestering transition metal ions and preventing Fenton reactions and are therefore largely proteins by nature (eg albumin, transferrin, lactoferrin, caeruloplasmin, haptoglobin, and ascorbic acid); and (3) enzyme antioxidants that are enzyme systems that function by catalysing the oxidation of other molecules (eg catalase and glutathione peroxidase). The equilibrium between antioxidant defence, repair systems and pro-oxidant mechanisms of cell damage may be tipped in favour of tissue destruction by increase in radical production or by a lowered antioxidant defence. ${ }^{2,9}$

In the early onset of periodontitis, polymorphonuclear leukocytes are functionally activated and exhibit increased free radical production. There is a delicate balance between the inflammatory-immune cell hypofunction and hyperfunction which are maintained by enzyme based mechanisms (which are activated following degranulation) and oxygen dependent pathways (produces free radicals species). ${ }^{9}$ ROS cause tissue damage through numerous ways that include DNA damage (base hydroxylation and lipooxygenase); protein damage (gingival hyaluronic acid and proteoglycans); lipid peroxidation and stimulation of proinflammatory cytokines. ${ }^{10}$ The antioxidant micronutrients are important not only for limiting oxidative and tissue damage, but also in preventing increased cytokine production, which is a result of prolonged activation of the immune response. Dietary and other enzymatic antioxidants protect the lipids of lipoproteins and other biomembranes against oxidative damage by intercept- ing oxidants before they can attack the tissues. It is important to have an adequate antioxidant intake from both diet and supplementation if needed, and can be a valuable adjunct in the treatment of chronic inflammatory dental disorders. ${ }^{11}$

\section{Antioxidants of clinical significance in dentistry}

A wide array of antioxidants has potential applications in dental therapeutics. Table 1 highlights some of the major antioxidants with their source, mechanism and clinical significance. ${ }^{12-16}$ Most of them are easily available as dietary supplements. Numerous views advocating the development of antioxidant based drugs have provided optimistic points in rationalising their development for the treatment of diseases of multifactorial origin. Some find their place in traditional spices used in Asian countries like turmeric and asafoetida. These agents act as scavengers, helping to prevent cell and tissue damage that could lead to cellular damage and disease. These traditional Eastern medicines have been in use for thousands of years. Western medicine, however, has not yet used them therapeutically although they show a considerable safety profile.

\begin{tabular}{|c|c|c|c|}
\hline Antioxidant & Source & Mechanism & Clinical significance (location) \\
\hline Beta carotene & $\begin{array}{l}\text { Dark green, orange or yellow } \\
\text { vegetables and fruits (spinach, } \\
\text { carrots, orange, squash, papaya, } \\
\text { mangoes and cantaloupes) }\end{array}$ & $\begin{array}{l}\text { Scavenging effect (traps peroxyl } \\
\text { free radicals in tissue at low } \\
\text { partial pressure of oxygen) }\end{array}$ & $\begin{array}{l}\text { Deficiency can lead to periodontal } \\
\text { destruction (Plasma) }\end{array}$ \\
\hline Alpha tocopherol & $\begin{array}{l}\text { Plant oil, margarine, wheat germ } \\
\text { and green, leafy vegetables }\end{array}$ & $\begin{array}{l}\text { Scavenging effect (breaks free } \\
\text { radical chain reaction ) }\end{array}$ & $\begin{array}{l}\text { Prostaglandin inhibitory effect can } \\
\text { contribute in reducing periodontal } \\
\text { inflammation. (Plasma, saliva, GCF) }\end{array}$ \\
\hline Ascorbic acid & Citrus fruits, cruciferous vegetables & $\begin{array}{l}\text { Scavenging and preventive (binds } \\
\text { metal ion) effect. Act by decreasing } \\
\text { nitrosation and also effects the activity } \\
\text { of leukocytes and macrophages }\end{array}$ & $\begin{array}{l}\text { Gingival bleeding is a common result } \\
\text { of ascorbate depletion. (Plasma, } \\
\text { saliva, GCF, synovial fluid) }\end{array}$ \\
\hline $\begin{array}{l}\text { Minerals (zinc, copper, } \\
\text { manganese, selenium) }\end{array}$ & $\begin{array}{l}\text { Legumes, nuts, whole grains, } \\
\text { green vegetables }\end{array}$ & $\begin{array}{l}\text { Enzyme activators and subunits of } \\
\text { antioxidant defense mechanism }\end{array}$ & Cytotoxic in action \\
\hline Curcuminoids & Turmeric & $\begin{array}{l}\text { Inhibits the generation of potent } \\
\text { free radicals like superoxide } \\
\text { and hydroxyl radicals }\end{array}$ & $\begin{array}{l}\text { Antibacterial, fungicidal, } \\
\text { wound healing, cytotoxic }\end{array}$ \\
\hline Epigallocatechin-3-gallate & Green Tea & Scavenging effect & $\begin{array}{l}\text { Reduce the risk of dental caries and plaque } \\
\text { formation. Effective in oral leukoplakia }\end{array}$ \\
\hline Spirulina fusiforms & Blue green micro algae & $\begin{array}{l}\text { Potent quencher of highly } \\
\text { reactive singlet oxygen }\end{array}$ & Effective in buccal squamous cell carcinoma \\
\hline Eugenol & Clove & $\begin{array}{l}\text { Scavenging and Preventive effect. } \\
\text { Enzyme activator for antioxidant action }\end{array}$ & Effective in toothache \\
\hline
\end{tabular}


Apart from the above mentioned antioxidants of significance in clinical dentistry there are numerous other compounds under research. Chilli pepper containing capsaicin, soybeans - genistein, tomatoes - lycopene, grapes - resvereterol, honey - caffeic acid phenethyl ester, garlic - diallyl sulphide, cabbage - indole-3-carbinol and broccoli containing sulphoraphane, are some of the important phytochemicals with redox active potential. ${ }^{17}$

\section{Controversial areas in antioxidant research}

Although antioxidant therapy could have a promising role in dental therapeutics, a few unaddressed issues need to be highlighted before it is firmly established (Table 2). ${ }^{10}$ The Danish Fitness and Nutrition Council has evaluated the basis for recommendations on the intake of antioxidants and has found limited reasons for increasing the recommended intake levels for some antioxidants. The amount of an antioxidant that may offer protection is not known and varies among individuals. High dose supplements of vitamin $\mathrm{E}$ and beta carotene may pose a health risk. High doses of vitamin A may have embryotoxic and teratogenic effects including neural crest, musculoskeletal and urogenital anomalies. Heavy consumption of carotene containing vegetables may cause amenorrhoea. Large doses of ascorbic acid may be associated with inhibition of ovarian steroidogenesis and increased probability of abortion. ${ }^{11}$

The International Alliance for Dietary Supplement Food Associations (IADSA) stated that, while few available meta analysis raise issues for debate, limitations identified by the authors themselves means that antioxidants do not offer much in maintaining health. But the scientific network in the IADSA, however, agreed that consumers could continue taking antioxidant food supplements for the benefits they provide. ${ }^{18}$

There seems to be a problem of drug interactions too. Antioxidants act as reducing agents to neutralise free radicals and if any therapeutic agent acts by releasing free radicals, there is a possibility in interference of its action by an antioxidant.

Table 2 Current issues of clinical importance before establishing antioxidants role in dental practice

\begin{tabular}{l|l} 
Issue & Current status \\
\hline Lack of evidence & RCTs are limited especially in dental therapeutics \\
\hline $\begin{array}{l}\text { Standardisation } \\
\text { Antioxidant cancer } \\
\text { prevention hypothesis }\end{array}$ & $\begin{array}{l}\text { Studies with special markers and outcomes are inadequate } \\
\text { in standardising antioxidants with respect to potency and safety }\end{array}$ \\
\hline $\begin{array}{l}\text { Drug interaction } \\
\text { Antioxidants in infertility }\end{array}$ & $\begin{array}{l}\text { Controversial. A small change in antioxidant dose (eg vitamin A, } \\
\text { ascorbic acid) may be embryotoxic and teratogenic }\end{array}$ \\
\hline
\end{tabular}

\section{Recommendations in dental practice}

Antioxidant therapy may be a double edged sword with negative and undesirable effects, if the safety threshold of the therapeutic dose is surpassed. If administration of antioxidant supplements decreases free radicals, it may interfere with essential defensive mechanisms for eradicating the organism of damaged cells, including those that are precancerous and cancerous. Hence there is a need for a specific endpoint while evaluating the efficacy of antioxidants. Clinical studies to identify biomarkers for antioxidant status and oxidative stress, cytokine multiplexing and gene arrays need to be done. The ratio of overall benefit:risk assessment needs to be evaluated when prescribing these in clinical dentistry. The following points should be considered strongly by the dental practitioners before considering antioxidant therapy:

- Has oxidative damage been implicated in the disease pathophysiology? (The disease should ideally have been associated with increased lipid peroxidation or oxidation of protein or DNA)

- Is the oxidative activity a central pathophysiological feature of the disease? (In some cases, oxidative damage may simply be an epiphenomenon resulting from the general tissue disruption and cell death. Even if it is not the underlying cause of the disease the resulting oxidative damage may cause preventable morbidity)
- Where is the oxidative damage occurring? This might be either intracellular or extracellular or in the lipid soluble environment of the membranes or lipoproteins. Will the antioxidants get to that area?

- Antioxidants could be beneficial in people with innate or acquired high baseline levels of reactive oxygen species but can be harmful in people with lower innate levels

- Currently few studies are available to extrapolate the therapeutic effects of antioxidants in dental practice. Although there has been promising results overall benefit: risk ratio should be considered.

Ongoing research illustrates positive findings for antioxidants in clinical dentistry. However, numerous issues need to be addressed due to lack of firm evidence. A substantial gap still exists in our knowledge of bioavailability, biotransformation and mechanism of action of antioxidants. Large scale RCTs and unbiased studies addressing the safety and standardisation issue of antioxidants in dentistry are also required.

1. Millen A E, Dodd K W, Subar A F. Use of vitamin, mineral, nonvitamin, and nonmineral supplements in the United States: the 1987, 1992, and 2000 National Health Interview Survey results. J Am Diet Assoc 2004; 104: 942-950.

2. Chapple I L, Brock G R, Milward M R, Ling N, Matthews J B. Compromised GCF total antioxidant capacity in periodontitis: cause or effect? J Clin Periodontol 2007; 34: 103-110.

3. Chapple I L. Role of free radicals and antioxidants in the pathogenesis of the inflammatory periodontal 
diseases. Clin Mol Pathol 1996; 49: M247-M255.

4. Nakamoto T, McCroskey M, Mallek H M. The role of ascorbic acid deficiency in human gingivitis: a new hypothesis. J Theor Biol 1984

108: 163-171.

5. Loesche W. The growth of nonsurgical treatment of periodontitis. Interview by Randall L. Valentine. Dent Today 1997; 16: 92, 94-97.

6. Maxwell S R. Prospects for the use of antioxidant therapies. Drugs 1995; 49: 345-361.

7. Tulunoglu O, Demirtas S, Tulunoglu I. Total antioxidant levels of saliva in children related to caries, age, and gender. Int J Paediatr Dent 2006; 16: 186-191.

8. Cerna H, Vesely J, Nastoupilova E et al. Periodontium and vitamin $\mathrm{E}$ and $\mathrm{A}$ in pregnancy. Acta Univ Palacki Olomuc Fac Med 1990; 125: 173-179.

9. Halliwell B, Gutteridge J M C, Cross C E. Free radicals, antioxidants, and human disease: where are we now? J Lab Clin Med 1992; 119: 598-620.

10. Carnelio S, Khan S A, Rodrigues G S. Free radicals and antioxidant therapy in clinical practice: to be or not to be? J Coll Physicians Surg Pak 2007; 17: 173-174.

11. Skibsted L H, Dragsted L 0 , Dyerberg J et al. Antioxidants and health. Ugeskr Laeger 2006; 168: 2787-2789.

12. Malone W F. Studies evaluating antioxidants and beta-carotene as chemo preventives. Am J Clin Nutr 1991; 53: 305S-313S.

13. Diplock A T. Antioxidant nutrients and disease prevention: an overview. Am J Clin Nutr 1991. 53: 189S-193S

14. Braga M E, Leal P F, Carvalho J E, Meireles M A. Comparison of yield, composition, and antioxidant activity of turmeric (Curcuma longa L.) extracts obtained using various techniques. J Agric Food Chem 2003; 51: 6604-6611.

15. Suganuma M, Okabe S, Sueoka N et al. Green tea and cancer chemoprevention. Mutat Res 1999; 428: 339-344.

16. Jirovetz L, Buchbauer G, Stoilova I et al. Chemical composition and antioxidant properties of clove leaf essential oil. J Agric Food Chem 2006; 54: 6303-6307.

17. Vattem D A, Mihalik K, Crixell S H, McLean R J. Dietary phytochemicals as quorum sensing inhibitors. Fitoterapia 2007; 78: 302-310.

18. International Experts Dispute Conclusions of Antioxidant Review 2007-02-27 - International Alliance of Dietary Supplement-Food Associations (IADSA). Available from http://www.npicenter. com/anm/templates/newsATemp.aspx?articleid $=1$ 7845\&zoneid=2 Accessed 12 June 2007. 